\title{
Substitution in Markusen's Classic Trade and Factor Movement Complementarity Models*
}

\author{
Maurice Schiff \\ World Bank and IZA
}

\begin{abstract}
Two classic papers on the relationship between trade and factor movement are Mundell (1957) and Markusen (1983). Mundell showed that substitution holds in the HeckscherOhlin model. Markusen challenged the substitution result and showed in five different models that removing barriers to factor movement results in complementarity under free trade, identical factor endowments and a change in any one of the other assumptions underlying the Heckscher-Ohlin model. This paper generalizes Markusen's analysis by considering: i) the elimination of barriers to factor movement under any protection level; and ii) a change in trade barriers under free factor movement. I show that: a) substitution holds under high protection; b) complementarity holds under low protection; and c) either substitution or complementarity hold for large increases (reductions) of low (high) protection rates.
\end{abstract}

World Bank Policy Research Working Paper 3974, August 2006

The Policy Research Working Paper Series disseminates the findings of work in progress to encourage the exchange of ideas about development issues. An objective of the series is to get the findings out quickly, even if the presentations are less than fully polished. The papers carry the names of the authors and should be cited accordingly. The findings, interpretations, and conclusions expressed in this paper are entirely those of the authors. They do not necessarily represent the view of the World Bank, its Executive Directors, or the countries they represent. Policy Research Working Papers are available online at http://econ.worldbank.org.

* I would like to thank Mohammad Amin, Arye Hillman, James Markusen, Hillel Rapoport and participants at a seminar at Bar-Ilan University for their useful comments. 


\section{Introduction}

The nature of the relationship between trade and factor movement has long been of interest to economists. The two classic papers in this literature are Mundell (1957) and Markusen (1983). Mundell used the Heckscher-Ohlin framework to show that international trade and factor movement are substitutes. ${ }^{1}$ Markusen (1983) provided a strong challenge to the conventional wisdom of substitution between trade and factor movement. He presents five models in which he assumes free trade and identical endowments, and successively changes one of the other assumptions underlying the Heckscher-Ohlin model. He shows that eliminating barriers to factor movement results in complementarity. ${ }^{2}$

This paper generalizes Markusen’s (1983) analysis by considering i) the elimination of barriers to factor movement under any protection level, and ii) a change in trade barriers under free factor movement. I show that substitution holds under high protection levels, complementarity holds under low protection levels, and either substitution or complementarity hold for large increases (reductions) of low (high) protection rates. ${ }^{3}$ The standard result that an increase and decrease in protection levels have opposite effects does not necessarily hold in this case.

\footnotetext{
${ }^{1}$ This result seemed intuitive and was therefore appealing to policymakers and analysts: labor could either export labor-intensive goods or migrate and produce them in the destination country. As the then President of Mexico Salinas said during the NAFTA negotiations: "We want to export goods, not people."

${ }^{2}$ This result obtains in Markusen and Svensson (1985) as well. Another study is Wong (1986), which derives necessary and sufficient conditions for substitutability and complementarity in a general equilibrium framework where international differences in factor endowments, tastes or technologies are possible. The framework differs from Markusen's in two ways. First, the paper considers the international movement of one factor, with the other factor assumed to be immobile. More importantly, it assumes that capital moves without its owners who repatriate the income from capital abroad. This complicates the analysis because solutions depend on the assumption about the good used for repatriation.

${ }^{3}$ Lopez and Schiff (1998) show in a three-factor model with migration costs and financing constraints that trade and skilled labor are substitutes while trade and unskilled labor are complements.
} 
The remainder of the paper is organized as follows. Section 2 presents Markusen’s (1983) model and complementarity result. Section 3 shows the conditions under which substitution and complementarity obtain under both liberalization of factor movement and changes in tariff rates. Section 4 concludes.

\section{Complementarity in Markusen’s (1983) Models}

The classic paper on complementarity between factor movement and trade is Markusen (1983). Markusen's objective was to challenge the received wisdom and demonstrate that trade and factor movement were as likely to be complements as substitutes.

He assumes identical relative factor endowments in both countries and successively changes one of the other basic assumptions underlying the Heckscher-Ohlin model, namely i) identical technologies in both countries; ii) identical homothetic preferences; iii) constant returns to scale; iv) perfect competition; and v) absence of domestic distortions in either country.

Markusen (1983) presents five models, each corresponding to a change in one of these assumptions. He states that the complementarity result in each of his models is based on the fact that “... each equilibrium involves a country having the relatively high price for the factor used intensively in the production of the export good” (pp. 342-343). Thus, factors move to the other country's sector that uses them intensively, resulting in an increase in trade. This implies that trade and factor movement are complements.

Given that the same finding is obtained in each of Markusen's models, I arbitrarily select the technological difference model to present the complementarity result 
in this section. The relationship between trade and factor movement under trade barriers is derived in Section 3.

Markusen considers a 2x2 model, with countries 1 and 2 and and sectors $X$ and $Y$. Markusen assumes identical endowments, free trade and prohibitive barriers to the movement of factors. Assuming all the other Heckscher-Ohlin conditions hold, including identical technology, implies that Country 1 and Country 2 are identical and autarky prevails.

Assume now that Country 1 has a Hicks-neutral technological advantage in sector $X$, i.e.:

$$
X_{j}=\lambda_{j} f\left(K_{X j}, L_{X j}\right), Y_{j}=g\left(K_{Y j}, L_{Y j}\right), \lambda_{1}>\lambda_{2},
$$

where $X_{j}\left(Y_{j}\right)=$ output of $X(Y)$ in Country $j(j=1,2), K_{i j}\left(L_{i j}\right)=$ capital (labor) in sector $i$ $\left(i=X, Y\right.$ ) in Country $j$, and $\lambda_{j}$ is the technology level in sector $X$ in Country $j$.

Country 1 has a comparative advantage in the production of $X$. Thus, it exports $X$ under free trade and imports $Y$. Assume arbitrarily that $X$ is labor-intensive and $Y$ is capital-intensive. Then, as Markusen has shown, $w_{1}>w_{2}, r_{1}<r_{2}$.

Eliminating the barriers to factor movement leads to labor flows from Country 2 to Country 1 and capital flows from Country 1 to Country 2. This increases the supply of labor and reduces the supply of capital in Country 1 , and vice versa for Country 2 . Thus, factors flow to the sector that uses them intensively, resulting in an increase in the production of the export sector in both countries and an increase in trade flows. Thus, factor movement and trade are complements. 
3. Relationship between Trade and Factor Movement under Trade BarriersMarkusen (1983)'s complementarity result was obtained by eliminating barriers to factor movement in the absence of protection. This paper generalizes Markusen’s analysis by i) examining the relationship between trade and factor movement under any trade barrier, and ii) considering the liberalization of both commodity and factor flows.

I show that substitution obtains for high trade barriers and complementarity for low barriers. ${ }^{4}$ The latter is presented in Section 3.1 and the former in Section 3.2. Section 3.3 examines quantum changes in trade barriers.

\subsection{Complementarity under Positive Tariffs}

Assume that the initial tariff is positive $(t>0)$. This has no impact on goods or factor prices under identical technologies because trade is absent in this case. Since the two countries are identical in factor endowments, technology, and preferences, it follows that goods and factor prices are identical under these conditions.

Assume now that, as in Section 2 above, Country 1 benefits from a Hicks-neutral technological advantage $\lambda_{1}>\lambda_{2}$ in its labor-intensive sector $X$. This implies that Country 1 exports $X$ and Country 2 exports $Y$. Section 2 showed that the technology shock raises the wage rate and reduces capital's rental rate in Country 1 relative to Country 2, i.e., $w_{1}$ $>w_{2}$ and $r_{1}<r_{2}$.

Given that trade takes place following the technology shock, a tariff in Country 2 raises the price of its labor-intensive importable $Y$, resulting in a lower rental rate $r_{2}$ and

\footnotetext{
${ }^{4}$ As in Mundell (1957), trade takes place at the protection levels under consideration.
} 
a higher wage rate $w_{2}$. Whether $w_{1}>w_{2}$ and $r_{1}<r_{2}$ or vice versa depends on the tariff rate.

Figure 1 depicts the relationship between the tariff rate and factor flows. The figure shows two distinct regions which are separated by the tariff rate $t^{*}$. At $t^{*}, w_{1}=w_{2}$ and $r_{1}=r_{2}$, the level of factor movement $M=0$, and the impact on $M$ of an infinitesimal change in $t$ is $\partial M / \partial t=0$.

The region where complementarity prevails is defined by the range of tariff rates $t$ $<t^{*}$ for which $w_{1}>w_{2}$ and $r_{1}<r_{2}$. In that range, tariff rates are too low to change the relationship between factor prices generated by the technological advantage in good $X$ in Country 1.

We examine the impact of changes in barriers to both trade and factor movement. Eliminating barriers to factor movement implies that capital flows to Country 2 and labor flows to Country 1 . This raises output of the export sector in both countries and reduces that of the import sector. Since trade increases as well, it follows that factor movement and trade are complements.

Second, a reduction in the tariff increases trade. It also lowers the price of good $Y$ in Country 2, thereby reducing the wage rate $w_{2}$ and raising the rental rate of capital $r_{2}$. Given that $w_{1}>w_{2}$ and $r_{1}<r_{2}$, it follows that the tariff reduction raises the international wedge in factor prices. This results in an increase in the movement of labor from Country 2 to Country 1 and an increase in the movement of capital from Country 1 to Country 2. Since both trade and the movement of labor and capital increase, trade and factor movement are complements. 
This is shown in Figure 1. The derivative $\partial M / \partial t<0$ in the region where $t<t^{*}$ and a reduction in the tariff, say from $t_{2}$ to $t_{3}$, raises both factor movement (from $M_{2}$ to $M_{3}$ ) and trade.

The same result obtains with a tariff in Country 1 . For a low tariff rate, the international factor price relationship is $w_{1}>w_{2}$ and $r_{1}<r_{2}$. A reduction in the tariff rate lowers the price of the capital-intensive importable good, resulting in a reduction in $r_{1}$ and an increase in $w_{1}$, thus raising the international wedge in factor prices. This increases factor flows and results in complementarity between trade and factor movement.

\subsection{Substitution under Positive Tariffs}

The region where substitution prevails is defined by the range of tariffs $t>t^{*}$ for which $w_{1}<w_{2}$ and $r_{1}>r_{2}$. These tariff rates are sufficiently high to overturn the relationship between international factor prices generated by the technological advantage in good $X$ in Country 1.

Liberalization of factor movement results in a movement of labor to Country 2 and capital to Country 1 . The factor movement reduces the output of the export sector in both countries and increases that of the import-competing sectors, resulting in a decline in trade. This implies that trade and factor movement are substitutes.

It is important to note that the pattern of trade is the same whether $t>t^{*}$ or $t<t^{*}$. What does change is the pattern of factor movement, with labor moving from Country 2 to Country 1 in the complementarity case and from Country 1 to Country 2 in the substitution case. Similarly, capital moves from Country 1 to Country 2 in the complementarity case and from Country 2 to Country 1 in the substitution case. 
A reduction in the tariff in Country 2 from $t$ to $t^{\prime}\left(t>t^{\prime}>t^{*}\right)$ raises the level of trade and, as before, lowers the wage rate $w_{2}$ and raises capital's rental rate $r_{2}$ in Country 2. This reduces the international wedge in factor prices, thereby reducing factor flows. In terms of Figure $1, \partial M / \partial t>0$ in that region and a reduction in the tariff, say from $t_{0}$ to $t_{1}$, reduces factor movement (from $M_{0}$ to $M_{1}$ ) and raises trade. Thus, trade and factor movement are substitutes. The same result obtains for a tariff in Country 1.

Thus, a technology shock in one of the two sectors in one of the two countries reduces the international wedge in factor prices under sufficiently high tariff rates and results in substitution between trade and factor movement.

Markusen (1983) showed that complementarity holds under free trade. This paper generalizes Markusen's analysis to the case of protectionist trade policy and shows that substitution holds for $t>t^{*}$ and complementarity for $t<t^{*}$. The latter includes the free trade case examined by Markusen.

Note that the standard result that an increase and decrease in protection levels have opposite effects does not necessarily hold here. For instance, at $t=t^{*}$ an increase and a decrease in protection both raise factor movement. Similarly, a decrease in protection for $t>t^{*}$ and an increase in protection for $t<t^{*}$ both reduce factor movement.

\subsection{Moving Across Substitution and Complementarity Regions}

This section examines quantum changes in trade policy. Assume that Country 2 starts with a tariff $t>t^{*}$ and liberalizes its trade to the point where the new tariff $t^{\prime}<t^{*}$. Thus, trade liberalization moves the economy from the substitution to the 
complementarity region, for instance in the case of a reduction in the tariff rate from $t=t_{0}$ to $t^{\prime}=t_{2}$.

Such a move does not necessarily imply that migration increases. For instance, with a reduction in the tariff rate from $t=t_{0}$ to $t^{\prime}=t_{2}$, migration falls from $M_{0}$ to $M_{2}$ and substitution obtains over that tariff range. If the tariff declines from $t=t_{0}$ to any tariff level $t^{\prime}<t_{3}$, migration increases, so that migration and trade are complements. Similarly, a quantum increase in protection may either increase or reduce the level of factor movement.

Hence, whether trade and factor movement are substitutes or complements depends on the initial tariff rate and the extent of its change.

\subsection{Prohibitive Tariff}

The prohibitive tariff rate at which a country no longer trades might be smaller than $t^{*}$. In that case, Markusen's result of complementarity between trade and factor movement would generalize to all tariff values $t \geq 0$.

\section{Concluding Comments}

Mundell (1958) used the Hecscher-Ohlin model to demonstrate that trade and factor movement are substitutes. Markusen (1983) challenged the received wisdom and showed that complementarity holds under free trade in models with identical endowments and a change in any one of the other assumptions of the Heckscher-Ohlin model. 
This paper generalizes Markusen’s (1983) analysis by considering

i) the elimination of barriers to factor movement under any protection level, and

ii) a change in trade barriers under free factor movement.

I show that:

a) substitution obtains under low trade barriers,

b) complementarity obtains under high trade barriers, and

c) a change in trade barriers from the low to the high tariff region or vice versa can result in either substitution or complementarity.

These findings have important policy implications. Policymakers are likely to select a different trade policy under factor mobility than under factor immobility, assuming that they take the impact of trade liberalization on factor movement into account. The change in trade policy would likely depend on the direction and extent of the associated change in factor movement and whether or not the authorities viewed this change as desirable. The latter would depend in part on the impact of the change in factor movement on the terms of trade.

\section{References}

Lopez, Ramon and Maurice Schiff. 1998. "Migration and the Skill Composition of the Labor Force: The Impact of Trade Liberalization in LDCs." Canadian Journal of Economics 31 (2): 318-36.

Markusen, James R. 1983. "Factor Movements and Commodity Trade as Complements.” Journal of International Economics. 14 (3-4): 341-356.

Markusen, James R. and L. E. O. Svensson. 1985. "Trade in goods and factors with international differences in technology.” International Economic Review 26: 175-92.

Mundell, Robert A. 1957. "International Trade and Factor Mobility." American Economic Review 47(3): 321-335.

Wong, Kar-yiu. 1986. “Are International Trade and Factor Mobility Substitutes?” Journal of International Economics 21: 25 - 43. 
Figure 1. Relationship between Factor Movement and Trade Policy in Markusen's Models

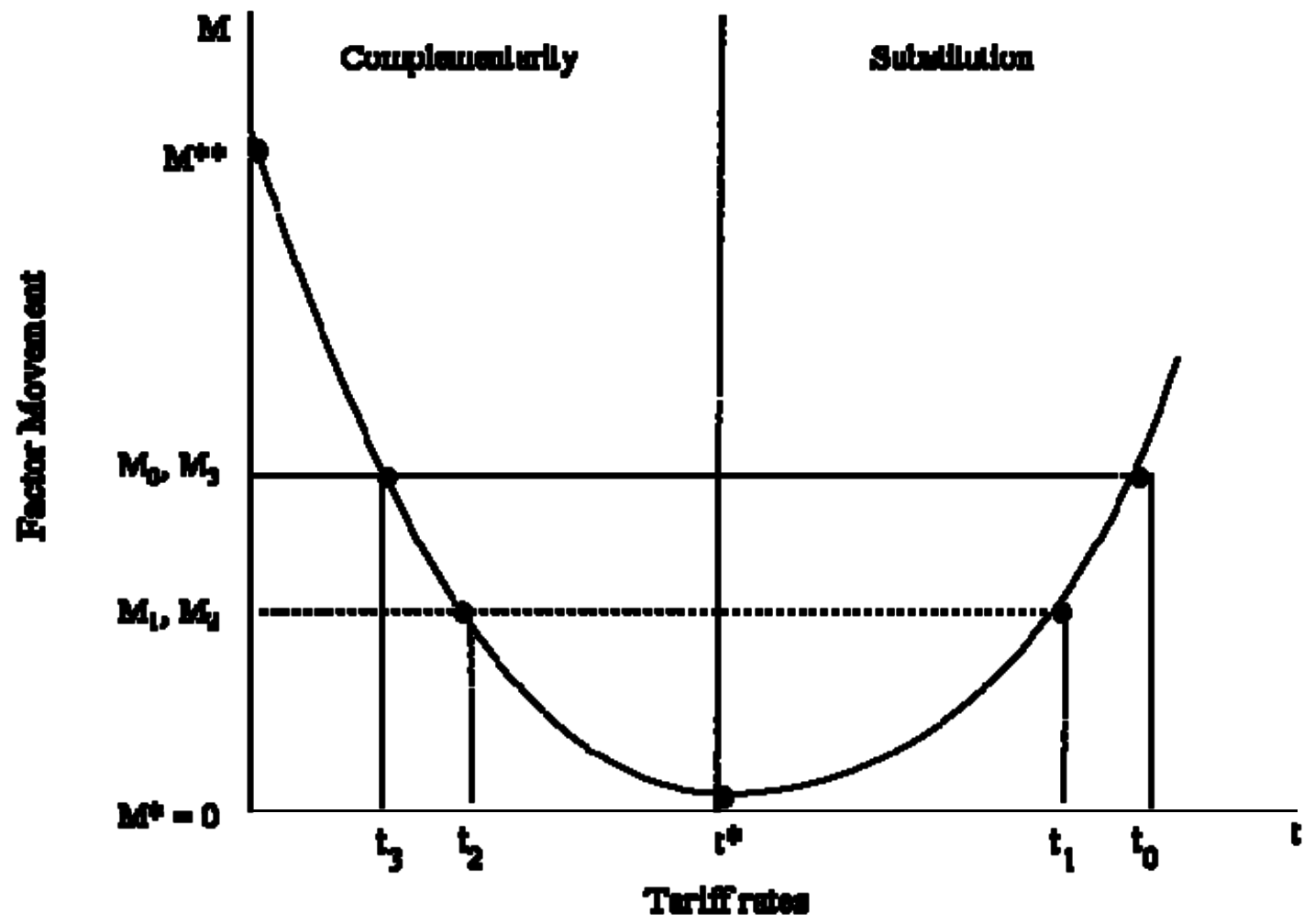

Mact $=$ H: $W_{1}-W_{2} ; r_{1}=$ h

$t<t_{1} W_{1}>W_{2} ; x<x_{1}$

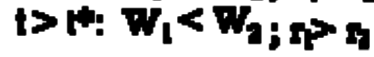

